\title{
Omega-3 carboxylic acids monotherapy and combination with statins in the management of dyslipidemia
}

This article was published in the following Dove Press journal:

Vascular Health and Risk Management

12 December 2016

Number of times this article has been viewed

\author{
Lane B Benes' \\ Nikhil S Bassi² \\ Michael H Davidson' \\ 'Department of Medicine, Section of \\ Cardiology, ${ }^{2}$ Department of Medicine, \\ University of Chicago, Chicago, \\ IL, USA
}

\begin{abstract}
The 2013 American College of Cardiology/American Heart Association guidelines on cholesterol management placed greater emphasis on statin therapy given the well-established benefits in primary and secondary prevention of cardiovascular disease. Residual risk may remain after statin initiation, in part because of triglyceride-rich lipoprotein cholesterol. Several large trials have failed to show benefit with non-statin cholesterol-lowering medications in the reduction of cardiovascular events. Yet, subgroup analyses showed a benefit in those with hypertriglyceridemia and lower high-density lipoprotein cholesterol level, a high-risk pattern of dyslipidemia. This review discusses the benefits of omega- 3 carboxylic acids, a recently approved formulation of omega-3 fatty acid with enhanced bioavailability, in the treatment of dyslipidemia both as monotherapy and combination therapy with a statin.
\end{abstract}

Keywords: omega-3 carboxylic acids, non-HDL-C, hypertriglyceridemia, residual risk, statin

\section{Introduction}

Statins are the cornerstone therapy for dyslipidemia. However, residual risk remains even for patients who are maximized on statin treatment. The atherogenic residual risk can be due to low-density lipoprotein cholesterol (LDL-C) levels that are not yet optimally controlled or elevation in triglyceride-rich lipoprotein cholesterol (TRL-C) that results in non-high-density lipoprotein cholesterol (HDL-C) above recommended targets. One of the strongest predictors of residual risk is hypertriglyceridemia and therefore elevation of non-HDL-C associated with low levels of HDL-C. The superiority of non-HDL-C versus LDL-C for major cardiovascular event (MACE) prediction was demonstrated in a meta-analysis of contemporary statin trials. ${ }^{1}$ Boekholdt et al's analysis using cut-off points of $100 \mathrm{mg} / \mathrm{dL}$ for LDL-C and $130 \mathrm{mg} / \mathrm{dL}$ for non-HDL$\mathrm{C}$ demonstrated that when there was discordance between the two measures (ie, only one was elevated), risk was more closely associated with non-HDL-C than LDL-C, illustrating that the elevated level of TRL-C was associated with increased coronary heart disease risk, even in the presence of low LDL-C $(<100 \mathrm{mg} / \mathrm{dL})$. To date, no largescale randomized controlled trial has been completed in which subjects were selected specifically on the basis of having elevated levels of triglyceride (TG) or TRL-C. As a result, the evidence base to support intervention based on levels of TGs and TRL-C is less robust than that for LDL-C as a target of therapy. However, $\sim 31 \%$ of the population in the US has a TG concentration $\geq 150 \mathrm{mg} / \mathrm{dL}$ and $16 \%$ have a level $\geq 200 \mathrm{mg}$ / $\mathrm{dL}^{2}$ Thus, the population attributable risk associated with this metabolic disturbance is large if one assumes a causal relationship. Moreover, from a clinical standpoint,
Correspondence: Michael H Davidson The University of Chicago Medicine, Section of Cardiology, 584I S. Maryland Avenue, MC 6080, Chicago, IL 60637, USA

Tel + I 7737021717

Fax +I 7738347300

Email mdavidso@bsd.uchicago.edu 
a substantial fraction of patients treated with statin therapy have residual elevation in non-HDL-C, reflecting increased TRL-C. 3,4

Omega-3 fatty acids (OM3-FAs) are widely used to lower TGs in patients with severe hypertriglyceridemia. A novel formulation containing omega-3 carboxylic acids (OM3-CAs, Epanova $^{\circledR}$, AstraZeneca, Wilmington, DE, USA), a complex mixture of the free fatty acids form containing eicosapentaenoic acid (EPA) and docosahexaenoic acid (DHA) as the two most abundant species ( $\sim 55 \%$ and $20 \%$, respectively), was recently approved by the US Food and Drug Administration as an adjunct to diet to reduce TGs in adults with levels of $\geq 500 \mathrm{mg} / \mathrm{dL}$. It is prescribed at a once-daily dose of $2 \mathrm{~g} /$ day (two capsules) or $4 \mathrm{~g} /$ day (four capsules).

The aim of this review is to discuss the benefits of OM3FAs, specifically OM3-CA, both alone and in combination with statins, in cardiovascular risk reduction, especially for those with hypertriglyceridemia and low HDL-C.

\section{Residual cardiovascular risk with statin therapy}

The benefits derived from statins in regard to cholesterol profiles and prevention of MACE are well established. Trials such as WOSCOPS, ${ }^{5}$ AFCAPS/TexCAPS, ${ }^{6}$ MEGA, ${ }^{7}$ ASCOT-LLA, ${ }^{8}$ and JUPITER ${ }^{9}$ have shown that statins improve lipid profiles while also reducing MACE rates when used for primary prevention. Statins have been shown to reduce MACE rates when administered for secondary prevention, as demonstrated by the $4 \mathrm{~S},{ }^{10} \mathrm{MIRACL},{ }^{11}$ and LIPID $^{12}$ trials. This was further supported when lower MACE rates were observed in those receiving a highintensity statin compared to a lower intensity statin in the IDEAL, ${ }^{13}$ PROVE-IT, ${ }^{14}$ and TNT $^{15}$ trials. Despite the remarkable benefits that have been demonstrated, those on statin therapy are not completely free from cardiovascular risk.

While some debate exists, several studies have identified an association between elevated TGs and cardiovascular disease (CVD). ${ }^{16-18}$ The expected TG reduction with statin use is about $5 \%-20 \%$ based on a 2010 meta-analysis by Nicholls et al, ${ }^{19}$ with greater reductions achieved with higher statin dosing. When assessed by baseline TG level, 70\%-80\% of subjects achieved TG levels $<150 \mathrm{mg} / \mathrm{dL}$ if baseline TG levels were $<200 \mathrm{mg} / \mathrm{dL}$; however, $0 \%-24 \%$ of subjects achieved TG $<150 \mathrm{mg} / \mathrm{dL}$ if baseline levels were $>300 \mathrm{mg} /$ $\mathrm{dL}$. Therefore, even with the potential for significant TG lowering, hypertriglyceridemia may persist for many patients on statin therapy.
It is common to observe low HDL-C in the setting of hypertriglyceridemia, especially in those with diabetes and/ or metabolic syndrome. Diabetics have an increased risk of coronary artery disease (CAD), ${ }^{20,21}$ and trials such as the Collaborative Atorvastatin Diabetes Study ${ }^{22}$ have demonstrated a reduction in MACE rates with statin administration for those with type 2 diabetes mellitus (DM). Type 2 DM (and to a lesser extent those with type $1 \mathrm{DM}$ ) is associated with abnormal lipid profiles, in particular higher non-HDL-C, ${ }^{23}$ lower HDL-C, ${ }^{24,25}$ higher TGs, ${ }^{24-26}$ and more small, dense LDL-C particles. ${ }^{25,26}$ Statin therapy improves several lipid parameters in those with this pattern of dyslipidemia. ${ }^{27}$ In addition to LDL and TG lowering, statins are more likely to raise HDL-C in those with baseline low HDL-C or high TGs. ${ }^{27}$ It is unclear whether this is a direct effect of statins, or if the improvements in HDL-C are secondary to reductions in TGs. While a causal relationship between rise in HDL-C levels and reduction in MACE has not been identified, those who experience HDL-C increases with statin therapy have lower MACE rates than those with a reduction in HDL-C. ${ }^{28}$ As discussed ahead, additional medications such as OM3-CA could potentiate this benefit provided by statins, or provide benefit in those intolerant to statins or who do not receive these desired changes in lipid profiles despite their use.

\section{Benefits of TG lowering in those with hypertriglyceridemia with or without low HDL-C}

Of the currently available medications for dyslipidemia, statins are known to provide the greatest protection from CVD. Yet, targeting abnormal lipid levels other than LDL-C with use of non-statin cholesterol medications can provide benefit, both with and without concomitant statin therapy. While the non-statin medications provide less protection than statins, it is still important to consider their advantages. This is especially true for those with hypertriglyceridemia and low HDL-C, a common and high-risk pattern of dyslipidemia.

One of the earliest large TG-lowering trials was the Helsinki Heart Study, which compared gemfibrozil versus placebo in 4081 men with non-HDL-C $\geq 200 \mathrm{mg} / \mathrm{dL}$ and without a history of CAD over a 5 -year period. ${ }^{29}$ The average baseline TG level was $175 \mathrm{mg} / \mathrm{dL}$ in the gemfibrozil group and $176 \mathrm{mg} / \mathrm{dL}$ in the placebo group, and the average baseline HDL-C was $47 \mathrm{mg} / \mathrm{dL}$ in both groups. Of the lipoproteins measured, the greatest change was seen in TGs, with a statistically significant reduction of $35 \%$ in the treatment group compared with a very small increase in the placebo group. There was also a reduction in non-HDL-C, LDL-C, and an 
increase in HDL-C. Results showed a significantly lower rate of cardiac end points in the gemfibrozil group and no difference in mortality over 6.2 years.

More recently, large trials evaluating outcomes of TG reduction have concluded that there is a lack of benefit. The majority of these studies used fibrates, which act via several mechanisms including activation of lipolysis of TG-rich lipoproteins. The Bezafibrate Infarction Prevention (BIP) study published in 2000 found no outcome benefit with bezafibrate compared to placebo in men and women with a history of CAD and dyslipidemia, specifically with HDL-C $\leq 45 \mathrm{mg} / \mathrm{dL}$, total cholesterol 180-250 mg/dL, LDL-C $\leq 180 \mathrm{mg} / \mathrm{dL}$, and $\mathrm{TG} \leq 300 \mathrm{mg} / \mathrm{dL} .{ }^{30}$ The greatest lipoprotein changes were a significant reduction in TG of $20.6 \%$ in the bezafibrate group compared with a $4.6 \%$ increase in the placebo group and a significant elevation in HDL-C cholesterol at $17.9 \%$ versus only $3.5 \%$ in the placebo group. There was no significant difference between the groups in regard to the primary end point of nonfatal or fatal myocardial infarction (MI) or sudden death; however, subgroup analyses showed that, in those with $\mathrm{TG} \geq 200 \mathrm{mg} / \mathrm{dL}$, there was a significant reduction of $39.5 \%$ $(p=0.02)$ in the primary end point. When further analyzed by baseline HDL-C level, those with HDL-C $<35 \mathrm{mg} / \mathrm{dL}$ and TG $\geq 200 \mathrm{mg} / \mathrm{dL}$ had a $41.8 \%(p=0.02)$ reduction in the primary end point, while those with HDL-C $\geq 35 \mathrm{mg} / \mathrm{dL}$ and TG $\geq 200$ had $35.9 \%$ reduction, which was not statistically significant $(p=0.33)$. This demonstrates that TG-lowering therapy may reduce MACE rates in those with significantly elevated TGs and low HDL-C. The Veterans Affairs HDL Intervention Trial (VA-HIT) found a significant $22 \%$ reduction in nonfatal MI's and CAD-related deaths with gemfibrozil use, which was associated with elevations in HDL-C. ${ }^{31}$ The population was men with a history of CAD with baseline average HDL-C of $32 \mathrm{mg} / \mathrm{dL}$ and TG of $162 \mathrm{mg} / \mathrm{dL}$, an unfavorable pattern of dyslipidemia. Uniquely, they had to have a baseline LDL-C $\leq 140 \mathrm{mg} / \mathrm{dL}$ to reduce confounding results from LDL-Clowering therapy. Similar to findings from subgroup analyses of the BIP study, subgroup analysis of VA-HIT found that men with the highest baseline quintile of TGs had a significant reduction in coronary events with gemfibrozil use.

Study of the type 2 diabetic population is important when considering the benefits of TG reduction given the greater prevalence of hypertriglyceridemia in combination with low HDL-C and small, dense LDL-C in this population. ${ }^{24-26}$ The Fenofibrate Intervention and Event Lowering in Diabetes (FIELD) study compared fenofibrate to placebo for primary and secondary prevention of cardiovascular events in those with type $2 \mathrm{DM}$, with $80 \%$ also meeting criteria for metabolic syndrome..$^{32}$ Over 5 years of follow-up, fenofibrate reduced cardiovascular events with a hazard ratio (HR) of 0.89 (95\% CI: $0.80-0.99, p<0.01)$. The group with the greatest reduction in cardiovascular events was those with baseline $\mathrm{TG} \geq 200 \mathrm{mg} /$ dL and low HDL-C, with a HR of 0.73 (95\% CI: 0.58-0.91, $p<0.05)$. In the Action to Control Cardiovascular Risk in Diabetes (ACCORD) Lipid trial, patients with diabetes on simvastatin monotherapy in the highest tertile of TGs $(\geq 204$ $\mathrm{mg} / \mathrm{dL})$ and the lowest tertile of HDL-C $(\leq 34 \mathrm{mg} / \mathrm{dL})$ had a cardiovascular event frequency of $17.3 \%$ compared with $10.1 \%$ in all other patients receiving simvastatin monotherapy. ${ }^{33}$ This subgroup of patients with high TG and low HDL-C represented $\sim 17 \%$ of the study population receiving statin monotherapy, but accounted for $25 \%$ of the cardiovascular events. The high TG and low HDL-C subgroup in the ACCORD Lipid trial had not only a greater cardiovascular event rate, but also a $29 \%$ relative risk reduction on fenofibrate combination therapy with simvastatin, compared with simvastatin monotherapy (12.4\% vs $17.3 \%$ events, $p=0.032$ ). However, the patients outside of this dyslipidemic subgroup did not benefit from the addition of fenofibrate to simvastatin therapy ( $10.1 \%$ vs $10.1 \%$ events, $p=0.06$ for the treatment-by-subgroup interaction).

Similar to the ACCORD Lipid trial, the Atherothrombosis Intervention in Metabolic Syndrome with Low HDL/High Triglycerides: Impact on Global Health Outcomes (AIMHIGH) study sought to determine if the TG-lowering and HDL-C-raising effects of niacin in combination with simvastatin $40-80 \mathrm{mg} \pm$ ezetimibe for goal LDL-C $<80 \mathrm{mg} / \mathrm{dL}$ would reduce the primary end point comprising cardiovascular events and death compared to those treated with simvastatin \pm ezetimibe alone. The results showed no benefit with the addition of extended-release niacin over 3 years despite significant improvements in TGs and HDL-C. ${ }^{34} \mathrm{~A}$ subgroup analysis published 2 years later found that in those with both the highest TG ( $>198 \mathrm{mg} / \mathrm{dL})$ and lowest HDL-C $(<33 \mathrm{mg} / \mathrm{dL})$ tertiles, the addition of extended-release niacin to simvastatin provided a greater reduction in the primary end point with HR of 0.74 , which almost reached statistical significance $(p=0.073){ }^{35}$ If TG and HDL-C cut-off points were slightly adjusted to $\geq 200$ and $<32 \mathrm{mg} / \mathrm{dL}$, respectively, a significant reduction in the primary end point was then observed with a HR of 0.64 ( $p=0.032)$.

Therefore, while it has been concluded that the trials looking at TG reduction with non-statin medications have not shown benefit in regard to cardiovascular outcomes, subgroup analyses have demonstrated a reduction in MACE rates in those with baseline elevated TGs and low HDL-C with or without concomitant statin use. The above trials did not use 
OM3-FAs for TG reduction, which have similar efficacy to the TG-lowering medications that were used and with generally better tolerability. For example, while both OM3-FA and fibrates can reduce TGs anywhere between $20 \%$ and $50 \%$, there is significant concern for drug-drug interactions with the use of fibrates, compared to the less concerning common side effect of gastrointestinal upset that is possible with OM3-FA use. ${ }^{36}$

\section{OM3-FA therapy}

OM3-FAs have been shown to improve lipid profiles in addition to providing other benefits; however, they are best known for their TG-lowering ability. The 2013 American College of Cardiology/American Heart Association (ACC/AHA) guidelines on cholesterol management do not specifically provide recommendations on the management of hypertriglyceridemia; instead they reference the AHA 2011 guidelines on TG management, which recommends lowering TG levels to ideally $<100 \mathrm{mg} / \mathrm{dL}$ through diet and exercise, including dietary OM3-FAs. ${ }^{2}$ If TGs remain elevated $>500 \mathrm{mg} / \mathrm{dL}$, it recommends considering the addition of medical therapy.

OM3-CA is a newer OM3-FA formulation that is in free fatty acid form. Older formulations contain fatty acid ethyl esters and therefore are in a pro-drug form, rendering them more dependent on pancreatic enzymatic activity. ${ }^{37-39}$ This is important, as those with CVD are instructed to reduce unhealthy fats in their diet, and those with severe

EPA+DHA levels at day 14

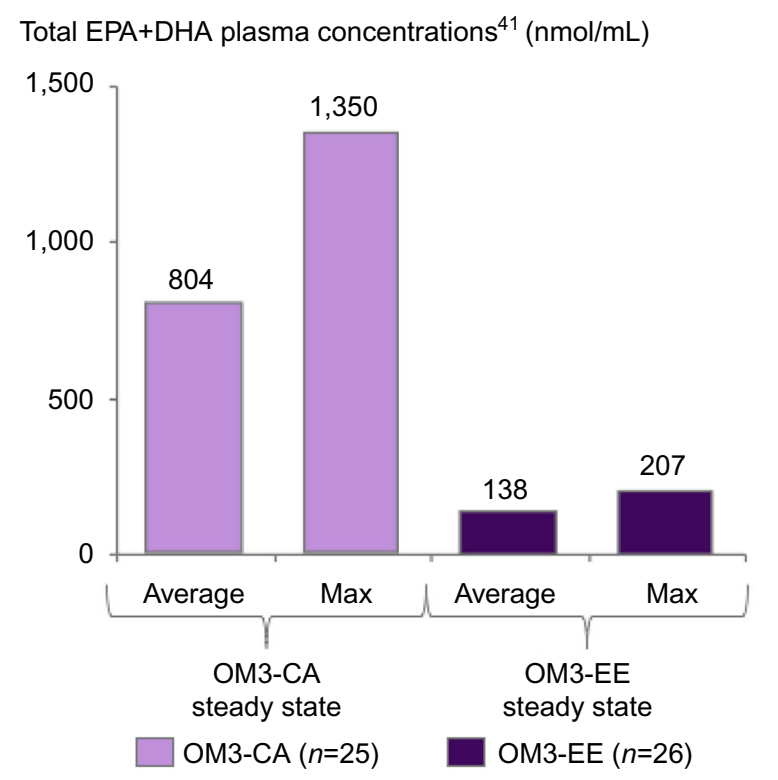

hypertriglyceridemia need to reduce all fats in their diet, decreasing stimulation of pancreatic lipase secretion. The Epanova Compared to Lovaza In a Pharmacokinetic Single-dose Evaluation (ECLIPSE) study showed about a 4-fold greater bioavailability of OM3-CA compared to omega-3-acid ethyl esters (OM3-EE, Lovaza ${ }^{\circledR}$, GlaxoSmithKline, Philadelphia, PA, USA) with a single low-fat meal. ${ }^{40}$ With a high-fat meal, the bioavailability of OM3-CA was still significantly greater than OM3-EE, but to a lesser extent (1.3-fold greater bioavailability). The ECLIPSE II trial also showed significantly greater serum levels of EPA and DHA for those on OM3-CA compared to OM3-EE while on a low-fat diet, however, after a longer time period of 14 days (Figure 1). ${ }^{41}$ Furthermore, OM3-CA was more effective than OM3-EE at lowering TG levels $(21 \%$ vs $8 \%, p=0.013)$ at 14 days. This suggests that a greater magnitude of benefit can be expected from OM3-CA compared to older OM3-FA formulations.

Treatment of severe hypertriglyceridemia with TGs $>500-900 \mathrm{mg} / \mathrm{dL}$ is recommended to help prevent acute pancreatitis. ${ }^{2,42}$ More debate exists regarding the benefits of treatment for those with moderate hypertriglyceridemia in the 150-500 mg/dL range. The EpanoVa fOr Lowering Very high triglyceridEs (EVOLVE) trial ${ }^{43}$ evaluated the TG-lowering efficacy of OM3-CA in those with baseline average TGs $\geq 500$ $\mathrm{mg} / \mathrm{dL}$, but $<2000 \mathrm{mg} / \mathrm{dL}$. EVOLVE compared those taking 2,3 , and $4 \mathrm{~g}$ daily of OM3-CA with a control group taking

Figure I OM3-CA bioavailability compared to OM3-EE as measured by steady-state levels of EPA and DHA in the ECLIPSE II trial.

Notes: Baseline adjusted - after 7 days following a TLC diet, subjects in both cohorts exhibited relatively similar baseline concentrations of total EPA+DHA (for OM3-CA: arithmetic mean concentration ranging from 175 to $197 \mathrm{nmol} / \mathrm{mL}$ and for OM3-EE from 172 to $193 \mathrm{nmol} / \mathrm{mL}$ ).

Abbreviations: AUC, area under the plasma concentration versus time curve; DHA, docosahexaenoic acid; EPA, eicosapentaenoic acid; Max, maximum; OM3-CA, omega-3 carboxylic acid; OM3-EE, omega-3 ethyl ester; TLC, therapeutic lifestyle changes.

EPA+DHA levels at day 14

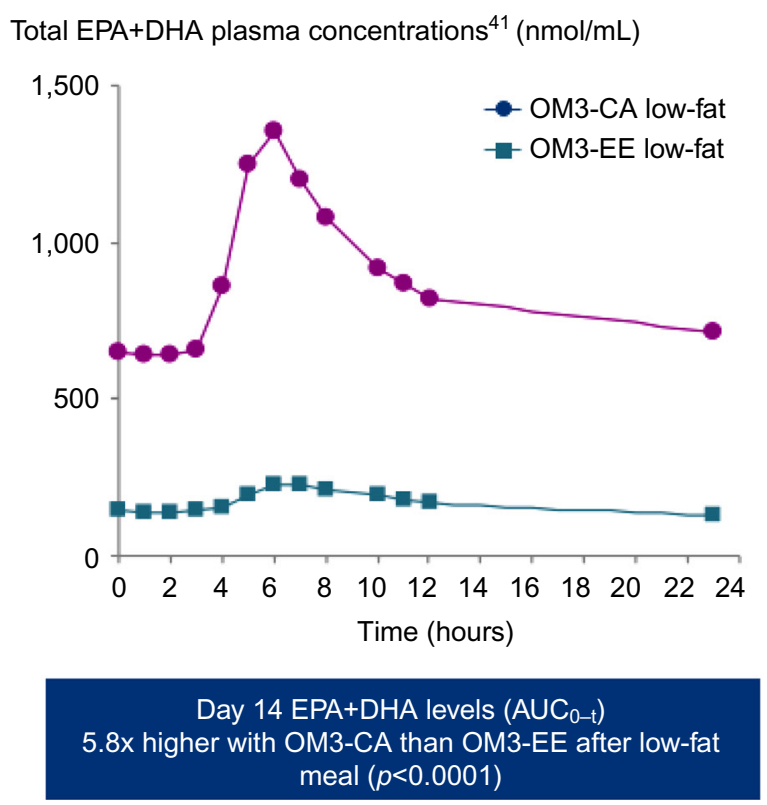


$4 \mathrm{~g}$ of olive oil daily over 12 weeks. A total of $34 \%-35 \%$ of subjects in each group were on a stable dose of statin or cholesterol absorption inhibitor or both prior to the study and were continued on the medication(s) during the trial. Fasting TGs were reduced by $25.9 \%$ in those taking $2 \mathrm{~g} / \mathrm{d}$ of OM3-CA ( $p<0.01$ vs olive oil), $25.5 \%$ in those taking $3 \mathrm{~g} / \mathrm{d}(p<0.01$ vs olive oil), and by $30.9 \%$ in those taking $4 \mathrm{~g} / \mathrm{d}(p<0.001$ vs olive oil), compared with a $4.3 \%$ reduction for the olive oil group. Other significant beneficial changes observed in the OM3-CA groups included a $6.9 \%-9.9 \%$ reduction in non-HDL-C, $26.4 \%-33 \%$ reduction in very low-density lipoprotein cholesterol (VLDL-C), 20.7\%-27.5\% reduction in remnant-like particle cholesterol, $11.1 \%-17.2 \%$ reduction in lipoprotein-associated phospholipase A2 (Lp-PLA ${ }_{2}$ ), and a $15.1 \%-23.2 \%$ reduction in arachidonic acid levels. There was a significant increase in LDL-C in groups receiving 2 and $4 \mathrm{~g} / \mathrm{d}$ of OM3-CA compared to olive oil, with increases from baseline of $19.2 \%$ and $19.4 \%$, respectively. However, apolipoprotein (Apo) B was not significantly changed from baseline, which supports the concept that OM3-CA does not increase the number of LDL-C particles but only the LDL-C size. Table 1 shows results from the EVOLVE trial. Subgroup analysis of those who were using a statin in the EVOLVE trial still experienced benefits in lipid levels, as shown in Figure $2 .{ }^{44}$ In particular, they experienced significant reductions in $\mathrm{TG}$ with the $4 \mathrm{~g} / \mathrm{d}$ dose of OM3-CA, significant reductions in non-HDL-C, and increases in HDL-C with both the 2 and $4 \mathrm{~g} / \mathrm{d}$ doses $(p<0.05$ for all).

The EVOLVE trial therefore showed that $2-4 \mathrm{~g}$ of daily OM3-CA for those with severe hypertriglyceridemia not only

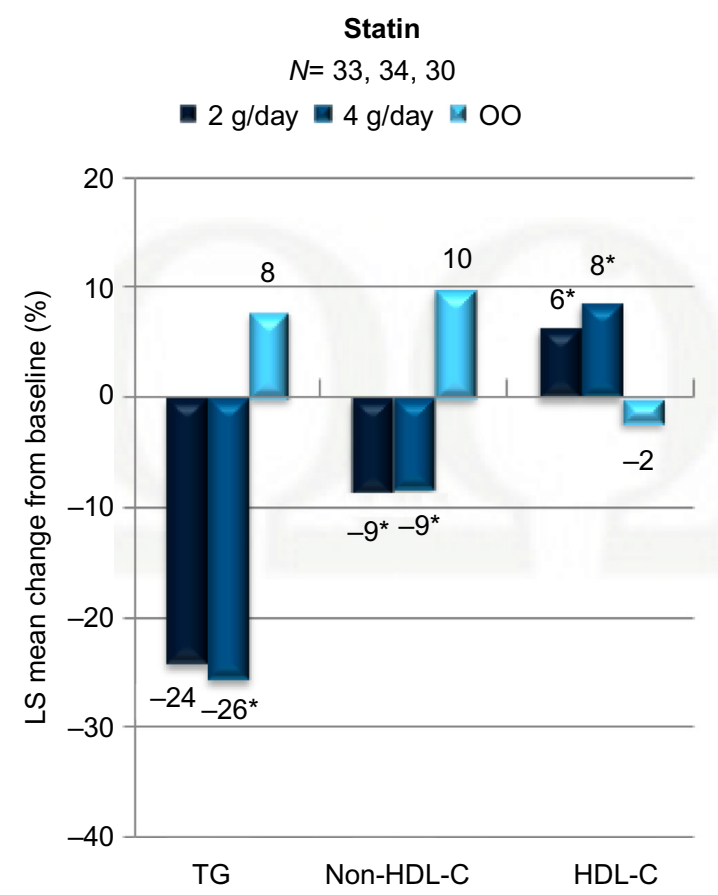

Figure 2 Changes in lipoprotein levels from baseline with omega-3 carboxylic acid use in those on statin therapy in the EVOLVE trial. ${ }^{44}$

Note: *Significant at $p<0.05$.

Abbreviations: EVOLVE, EpanoVa fOr Lowering Very high triglyceridEs; HDL-C, high-density lipoprotein-cholesterol; LS, least square; OO, olive oil; TG, triglyceride.

reduces TG remarkably, but also reduces other atherogenic lipoprotein particles. It reduces inflammation, as indicated by reductions in Lp-PLA, and reduces platelet activation, as indicated by reductions in arachidonic acid. Despite elevations in LDL-C, the EVOLVE study authors concluded that a net benefit in cardiovascular protection is expected given reductions in

Table I Summary of EVOLVE and ESPRIT trials

\begin{tabular}{|c|c|c|c|c|c|c|}
\hline & \multicolumn{3}{|l|}{ ESPRIT $^{54}$} & \multicolumn{3}{|l|}{ EVOLVE $^{43}$} \\
\hline \multirow[t]{2}{*}{ Subjects } & \multicolumn{3}{|l|}{$N=647$} & \multicolumn{3}{|l|}{$N=399$} \\
\hline & \multicolumn{3}{|c|}{$\mathrm{TG} \geq 200$ and $<500 \mathrm{mg} / \mathrm{dL}$ on maximally tolerated statin } & \multicolumn{3}{|c|}{ TG $\geq 500$ and $<2000 \mathrm{mg} / \mathrm{dL}$ with or without a statin } \\
\hline Duration & \multicolumn{3}{|c|}{6 weeks } & \multicolumn{3}{|c|}{12 weeks } \\
\hline \multirow[t]{3}{*}{ Results } & \multicolumn{3}{|c|}{ Percent change from baseline } & \multirow{2}{*}{\multicolumn{3}{|c|}{$\begin{array}{l}\text { Percent change from baseline } \\
\text { ( } p \text {-value of treatment vs } O O \text { control) }\end{array}$}} \\
\hline & \multicolumn{3}{|c|}{ ( $p$-value of treatment vs $O O$ control) } & & & \\
\hline & $4 \mathrm{~g} / \mathrm{d} O \mathrm{O}$ control & $2 \mathrm{~g} / \mathrm{d} \mathrm{OM} 3-\mathrm{CA}$ & $4 \mathrm{~g} / \mathrm{d} O M 3-C A$ & $4 \mathrm{~g} / \mathrm{d} O \mathrm{O}$ control & $2 \mathrm{~g} / \mathrm{d} O M 3-C A$ & $4 \mathrm{~g} / \mathrm{d} \mathrm{OM} 3-\mathrm{CA}$ \\
\hline TG & -5.9 & $-14.6 * * *$ & $-20.6 * * *$ & -4.3 & $-25.9 * *$ & $-30.9 * * *$ \\
\hline Total-C & 0.5 & $-1.7^{*}$ & $-3.8 * * *$ & 3.2 & $-5.4^{*}$ & $-7.5^{* *}$ \\
\hline Non-HDL-C & -0.9 & $-3.9 *$ & $-6.9 * * *$ & 2.5 & $-7.6^{*}$ & $-9.6 * *$ \\
\hline HDL-C & 2.2 & 2.6 & 3.3 & 1.9 & 7.4 & 5.8 \\
\hline LDL-C & I.I & $4.6 *$ & $\mathrm{I} .3$ & 3.0 & $19.2^{* *}$ & $19.4^{* * * *}$ \\
\hline VLDL-C & -5.9 & $-14.3 * *$ & $-21.5^{* * * *}$ & -8.5 & $-26.6 * *$ & $-33.0 * * *$ \\
\hline ApoB & 0.6 & 0.7 & $-2 . I^{*}$ & 0.9 & 3.8 & 3.8 \\
\hline ApoAl & 0.3 & -0.8 & $-1.2^{*}$ & 5.9 & $0.0 * *$ & $-0.9 * *$ \\
\hline
\end{tabular}

Notes: Those randomized to the $2 \mathrm{~g} / \mathrm{d}$ dose of OM3-CA also received a $2 \mathrm{~g} / \mathrm{d}$ dose of OO. A $3 \mathrm{~g} / \mathrm{d}$ dose was also used in EVOLVE, however the values are not shown here. $*_{p}<0.05,{ }^{* *} p<0.01, * * * p<0.001$.

Abbreviations: OM3-CA, omega-3 carboxylic acid; OO, olive oil. 
non-HDL-C and no change in Apo B, both of which have been shown to be stronger predictors of cardiovascular risk compared to LDL-C. ${ }^{1,45}$ Furthermore, there were significant reductions in VLDL-C and remnant-like particles, both of which are atherogenic. OM3-CA was determined to be safe and well tolerated, with the main side effects being mild-to-moderate gastrointestinal events, including diarrhea, eructation, and nausea, leading to discontinuation of the drug in $3 \%$ of participants. Overall, more subjects discontinued treatment in the OM3-CA group at $5 \%-7 \%$, compared to $0 \%$ in the olive oil group.

Findings from EVOLVE are consistent with the studies that preceded it, showing reductions in TGs with OM3-FA use in populations with moderate hypertriglyceridemia, some of which also showed reductions in the number of small, dense LDL-C particles. ${ }^{46-49}$ Specifically, Mori et al showed an $18 \%$ and $20 \%$ reduction in TG relative to placebo in hyperlipidemic men given DHA and EPA, respectively, without significant changes in other lipoproteins, with the exception of a $6.7 \%$ increase in LDL-C for those given DHA ${ }^{46}$ DHA use resulted in a significant increase in LDL particle size. In 2007 , Kelley et al found a $24 \%$ reduction in TG levels after 45 days of DHA supplementation in men with hypertriglyceridemia, in addition to reductions in total VLDL-C $(92 \%)$ and IDL-C (53\%). ${ }^{48}$ DHA use increased LDL-C concentration as well as LDL particle size and decreased VLDL size in fasting samples. A reduction in inflammation has also been demonstrated with other OM3-FA formulations; the MARINE and ANCHOR studies found similar reductions in Lp-PLA $A_{2}$ as well as other markers of inflammation in those with hypertriglyceridemia taking icosapent ethyl, a highpurity formulation of EPA. ${ }^{50}$ Additional benefits of OM3-FA have been described, including associations with a reduction in CAD, cardiac arrhythmia suppression, and a reduction in platelet aggregation to provide an antithrombotic effect. ${ }^{51}$

\section{OM3-FAs and statin combination therapy}

Understanding the effects of OM3-FA and statin combination therapy is important because the majority of patients with hypertriglyceridemia often have an indication for a statin. From a mechanistic standpoint, they differ in that OM3-FA lowers TGs primarily by reducing hepatic TG secretion as well by increasing the rate of clearance from the circulation, whereas statins inhibit $\mathrm{HMG}-\mathrm{CoA}$ reductase, leading to decreased cholesterol production, especially LDL-C. OM3FAs achieve these effects by altering gene expression, which includes upregulating genes encoding lipoprotein lipase and proteins involved in fatty acid oxidation, and downregulating genes encoding proteins involved in lipogenesis. ${ }^{52}$ One of the early large trials investigating combination therapy was the
2007 Combination of prescription Omega-3 with Simvastatin (COMBOS) study, which showed significant improvement in non-HDL-C with TG-lowering from the addition of OM3-EE to simvastatin in those with TG levels $\geq 200$ and $<500 \mathrm{mg} / \mathrm{dL}$ compared to simvastatin alone. ${ }^{53}$ Results showed significant reductions in TG and VLDL-C levels in the OM3-FA + simvastatin group compared to simvastatin alone after 8 weeks with nonsignificant changes in LDL-C levels in either group.

The Epanova Combined with a Statin in Patients with Hypertriglyceridemia to Reduce non-HDL Cholesterol (ESPRIT) study published more recently in 2013 was similar to COMBOS; however, it was larger and used the newer OM3-FA formulation, OM3-CA. ${ }^{54}$ The study showed improvements in cardiovascular risk profiles in patients with persistent hypertriglyceridemia ( $\mathrm{TG} \geq 200$ and $<500 \mathrm{mg} / \mathrm{dL}$ ) despite statin therapy using either 2 or $4 \mathrm{~g}$ of daily OM3-CA compared to olive oil and placebo. Results showed significant reductions in non-HDL-C by $3.9 \%$ and $6.9 \%$ in the 2 and $4 \mathrm{~g} / \mathrm{d}$ doses, respectively, compared to $0.9 \%$ reduction with olive oil ( $p<0.05$ and $<0.001$, respectively), significant reductions in TG by $14.6 \%$ and $20.6 \%$, respectively, compared to $5.9 \%$ in olive oil ( $p<0.001$ for both), and significant reductions in total cholesterol and VLDL-C compared to olive oil (all at least $p<0.05$ ) (Figure 3). There was also a significant reduction in arachidonic acid in both OM3-CA groups compared to olive oil ( $p<0.001$ for both), indicating decreased platelet activation with OM3-CA. This is a very welcomed benefit because statins raise arachidonic acid levels. ${ }^{55}$ Table 1 shows results from ESPRIT. A subgroup analysis of subjects with low HDL-C $(<42 \mathrm{mg} / \mathrm{dL}$ for men and $<47 \mathrm{mg} / \mathrm{dL}$ for women) found a significant reduction in small LDL-C, VLDL-C, remnant lipoprotein, non-HDL-C, and TG when comparing the OM3-CA $4 \mathrm{~g} / \mathrm{d}$ group to the olive oil placebo group (compositional cholesterol changes with OM3-CA in patients with hypertriglyceridemia paired with low HDL-C: a subanalysis from the ESPRIT trial, poster presentation AHA 2015). Additionally, those with low HDL-C in the OM3-CA $4 \mathrm{~g} / \mathrm{d}$ group had significantly increased large LDL-C and HDL2:HDL3 when compared to placebo. Significant changes in Apo B100, Apo B48, and PCSK9 levels were not observed.

A later analysis of ESPRIT found that small LDL-C particles were significantly reduced in those taking the $4 \mathrm{~g} / \mathrm{d}$ dose compared to olive oil, ${ }^{56}$ similar to findings from the subgroup analysis of those with low HDL-C (compositional cholesterol changes with OM3-CA in patients with hypertriglyceridemia paired with low HDL-C: a subanalysis from the ESPRIT trial, poster presentation AHA 2015). Furthermore, the $4 \mathrm{~g} / \mathrm{d}$ dose brought significant reductions in Lp-PLA 2 and both OM3-CA doses brought significant reductions in Apo 


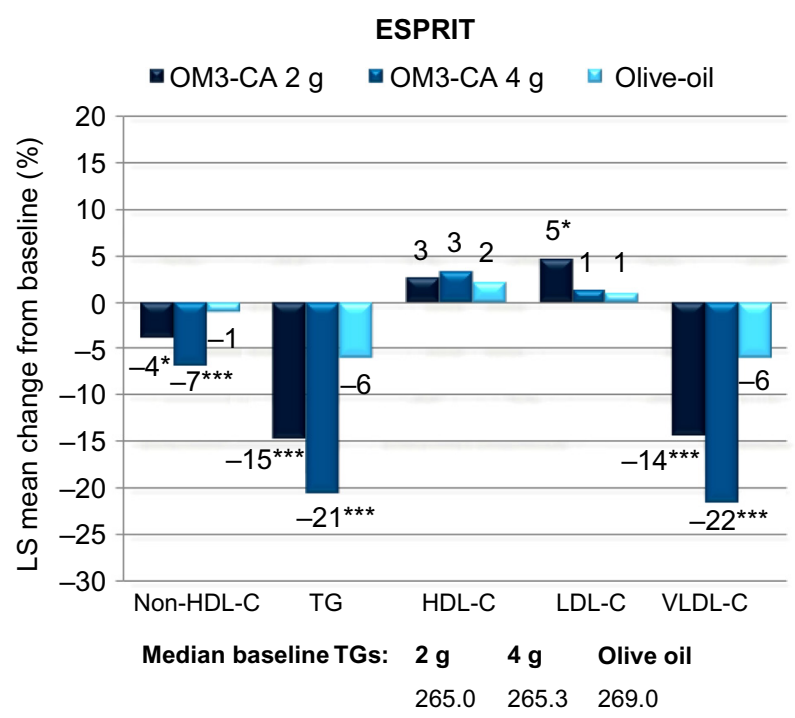

Figure 3 Change in lipoprotein levels with omega- 3 carboxylic acid compared to olive oil placebo.

Notes: *Significant at $p<0.05$. $* * *$ Significant at $p<0.001$.

Abbreviations: ESPRIT, Epanova Combined with a Statin in Patients with Hypertriglyceridemia to Reduce non-HDL Cholesterol; HDL-C, high-density lipoprotein-cholesterol; LDL-C, low-density lipoprotein-cholesterol; LS, least square; OM3-CA, omega-3 carboxylic acid, TG, triglyceride; VLDL-C, very lowdensity lipoprotein cholesterol.

CIII compared to placebo. The Lp-PLA 2 -lowering ability of OM3-CA is worth noting because fenofibrate increases Lp-PLA ${ }_{2}{ }^{57}$

Outcome data have shown a benefit of adding OM3-FA to statins as well. The Japan EPA Lipid Intervention Study found a reduction in cardiovascular event rates in Japanese patients taking both EPA and a statin compared to statin alone. ${ }^{58}$ The rate of MACE was reduced by $19 \%$ in the EPA + statin group, in which $2.8 \%$ experienced an event over a followup of 5 years, compared with $3.5 \%$ in controls $(p=0.011)$. When analyzing groups based on the presence of baseline $\mathrm{CAD}$, those receiving EPA + statin for primary prevention had lower MACE rates compared to controls; however, this was not statistically significant. In contrast, those receiving EPA + statin for secondary prevention had a statistically significant reduction in MACE. Baseline TG's in both groups was $1.7 \mathrm{mmol} / \mathrm{L}(151 \mathrm{mg} / \mathrm{dL})$, HDL-C was $1.5 \mathrm{mmol} / \mathrm{L}$ ( $58 \mathrm{mg} / \mathrm{dL})$, and LDL-C was $4.7 \mathrm{mmol} / \mathrm{L}(182 \mathrm{mg} / \mathrm{dL})$. The ongoing Outcomes Study to Assess STatin Residual Risk Reduction with EpaNova in HiGh Cardiovascular Risk PatienTs with Hypertriglyceridemia (STRENGTH) will help determine the effects of OM3-CA on cardiovascular event rates (http://clinicaltrials.gov/show/NCT02104817). The STRENGTH trial is currently enrolling 13,000 patients with hypertriglyceridemia and low HDL-C who are on statin therapy, randomizing them to $4 \mathrm{~g}$ of daily OM3-CA vs corn oil as placebo. If results show a reduction in MACE with the addition of OM3-CA to statin therapy in this population, it will be consistent with subgroup analyses of TG-lowering trials as discussed above.

Statins and OM3-FA are both generally well tolerated. Myopathy is the greatest adverse effect with statin use, observed at a rate of about $10.5 \%{ }^{59}$ The OM3-CA trials found the drug to be safe and highly tolerable, with the most common side effect being mild gastrointestinal symptoms, including diarrhea, eructation, and nausea. Statins and OM3FA appear to have low risk of drug-drug interactions, and therefore are tolerated well in combination. Specific studies have been conducted with coadministration of icosapent ethyl and atorvastatin ${ }^{60}$ as well as between OM3-EE and statins. ${ }^{61-63}$ No pharmacokinetic interactions were found. Despite some biological plausibility, no clinical evidence exists that the coadministration of statins and OM3-FAs is harmful.

\section{Conclusion}

Based on subgroup analyses of trials investigating TGlowering therapies, those with hypertriglyceridemia and low HDL-C may benefit from TG-lowering therapy either alone or in combination with a statin. The benefits in lipoprotein levels with OM3-CA use both alone and with a statin have been well demonstrated in trials such as EVOLVE and ESPRIT. Previous research has also demonstrated benefits with OM3-FA use, which is likely enhanced with OM3-CA given its greater bioavailability compared to older formulations. Furthermore, OM3-CA was found to have a high level of safety and tolerability, which may be less true of other non-statin cholesterol-lowering medications, such as drug-drug interaction concerns with fibrates. ${ }^{36}$ While OM3-FAs have historically been used in the treatment in hypertriglyceridemia, trials using OM3-CA and other OM3-FA formulations have shown benefits in non-HDL-C, LDL-C particle size, and favorable changes in markers of inflammation and platelet activation, in addition to reductions in TGs.

\section{Limitations and future directions}

When considering OM3-FA use alone or in combination with statins, changes in formulation may reduce the applicability of earlier studies with older formulations. It is expected that the benefits seen with older formulations would apply because the greatest change with OM3-CA is improved bioavailability. Compared to statin trials, studies investigating OM3-FA use are relatively small. A large population clinical trial with 
OM3-CA use would provide more insight into its benefits for those with hypertriglyceridemia. In particular, investigation of combination OM3-CA and statin therapy, and OM3-CA monotherapy for those with a contraindication to statin use, would be beneficial. Fortunately, investigation is underway to determine if OM3-CA combined with a statin reduces MACE rates in patients with hypertriglyceridemia and elevated cardiovascular risk in the STRENGTH trial, which is enrolling 13,000 elevated-risk patients. If the STRENGTH trial does indeed show a reduction in cardiovascular events, it would be consistent with the subgroup analyses of patients with hypertriglyceridemia in the BIP, VA-HIT, FIELD, ACCORD Lipid, and AIM-HIGH trials, which showed a reduction in cardiovascular outcomes in these high-risk patients who were treated with TG-lowering therapy alone or with a statin.

\section{Disclosure}

Michael H Davidson was the Chief Medical Officer of Omthera until June of 2015. Omthera Pharmaceuticals clinically developed omega-3 carboxylic acid for FDA approval and was acquired by Astra Zeneca in July, 2013. The authors report no other conflicts of interest in this work.

\section{References}

1. Boekholdt SM, Arsenault BJ, Mora S, et al. Association of LDL cholesterol, non-HDL cholesterol, and apolipoprotein B levels with risk of cardiovascular events among patients treated with statins: a metaanalysis. JAMA. 2012;307(12):1302-1309.

2. Miller M, Stone NJ, Ballantyne C, et al. American Heart Association Clinical Lipidology, thrombosis, and prevention committee of the council on nutrition, physical activity, and metabolism; council on arteriosclerosis, thrombosis and vascular biology; council on cardiovascular nursing; council on the kidney in cardiovascular disease. Triglycerides and cardiovascular disease: a scientific statement from the American Heart Association. Circulation. 2011;123(20):2292-2333.

3. Maki KC, Galant R, Davidson MH. Non-high-density lipoprotein cholesterol: the forgotten therapeutic target. Am J Cardiol. 2005;96(9A): $59 \mathrm{~K}-64 \mathrm{~K}$

4. Jones PH, Nair R, Thakker KM. Prevalence of dyslipidemia and lipid goal attainment in statin-treated subjects from 3 data sources: a retrospective analysis. J Am Heart Assoc. 2012;1(6):e001800.

5. Shepherd J, Cobbe SM, Ford I, et al. Prevention of coronary heart disease with pravastatin in men with hypercholesterolemia. West of Scotland Coronary prevention study group. NEngl J Med. 1995;333(20):1301-1307.

6. Downs JR, Clearfield M, Weis S, et al. Primary prevention of acute coronary events with lovastatin in men and women with average cholesterol levels: results of AFCAPS/TexCAPS. Air Force/Texas Coronary Atherosclerosis Prevention Study. JAMA. 1998;279(20):1615-1622.

7. Nakamura H, Arakawa K, Itakura H, et al; MEGA Study Group. Primary prevention of cardiovascular disease with pravastatin in Japan (MEGA study): a prospective randomised controlled trial. Lancet. 2006;368(9542):1155-1163.

8. Sever PS, Dahlöf B, Poulter NR, et al; ASCOT Investigators. Prevention of coronary and stroke events with atorvastatin in hypertensive patients who have average or lower-than-average cholesterol concentrations, in the Anglo-Scandinavian Cardiac Outcomes Trial-Lipid Lowering Arm (ASCOT-LLA): a multicentre randomised controlled trial. Lancet. 2003;361(9364):1149-1158.
9. Ridker PM, Danielson E, Fonseca FA, et al; JUPITER Study Group. Rosuvastatin to prevent vascular events in men and women with elevated C-reactive protein. N Engl J Med. 2008;359(21):2195-2207.

10. [No authors listed] Randomised trial of cholesterol lowering in 4444 patients with coronary heart disease: the Scandinavian Simvastatin Survival Study (4S). Lancet. 1994;344(8934):1383-1389.

11. Schwartz GG, Olsson AG, Ezekowitz MD, et al; Myocardial Ischemia Reduction with Aggressive Cholesterol Lowering (MIRACL) Study Investigators. Effects of atorvastatin on early recurrent ischemic events in acute coronary syndromes: the MIRACL study: a randomized controlled trial. JAMA. 2001;285(13):1711-1718.

12. [No authors listed] Prevention of cardiovascular events and death with pravastatin in patients with coronary heart disease and a broad range of initial cholesterol levels. The Long-Term Intervention with Pravastatin in Ischaemic Disease (LIPID) Study Group. $N$ Engl J Med. 1998;339(19):1349-1357.

13. Pedersen TR, Faergeman O, Kastelein JJ, et al; Incremental Decrease in End Points Through Aggressive Lipid Lowering (IDEAL) Study Group. High-dose atorvastatin vs usual-dose simvastatin for secondary prevention after myocardial infarction: the IDEAL study: a randomized controlled trial. JAMA. 2005;294(19):2437-2445.

14. Cannon CP, Braunwald E, McCabe CH, et al; Pravastatin or Atorvastatin Evaluation and Infection Therapy-Thrombolysis in Myocardial Infarction 22 Investigators. Intensive versus moderate lipid lowering with statins after acute coronary syndromes. $N$ Engl J Med. 2004;350(15): $1495-1504$.

15. LaRosa JC, Grundy SM, Waters DD, et al; Treating to New Targets (TNT) Investigators. Intensive lipid lowering with atorvastatin in patients with stable coronary disease. $N$ Engl J Med. 2005;352(14):1425-1435.

16. Nordestgaard BG, Benn M, Schnohr P, Tybjaerg-Hansen A. Nonfasting triglycerides and risk of myocardial infarction, ischemic heart disease, and death in men and women. JAMA. 2007;298(3):299-308.

17. Sarwar N, Danesh J, Eiriksdottir G, et al. Triglycerides and the risk of coronary heart disease: 10,158 incident cases among 262,525 participants in 29 Western prospective studies. Circulation. 2007;115(4):450-458.

18. Hokanson JE, Austin MA. Plasma triglyceride level is a risk factor for cardiovascular disease independent of high-density lipoprotein cholesterol level: a meta-analysis of population-based prospective studies. J Cardiovasc Risk. 1996;3(2):213-219.

19. Nicholls SJ, Brandrup-Wognsen G, Palmer M, Barter PJ. Meta-analysis of comparative efficacy of increasing dose of Atorvastatin versus Rosuvastatin versus Simvastatin on lowering levels of atherogenic lipids (from VOYAGER). Am J Cardiol. 2010;105(1):69-76.

20. Lemp GF, Vander Zwaag R, Hughes JP, et al. Association between the severity of diabetes mellitus and coronary arterial atherosclerosis. $\mathrm{Am}$ J Cardiol. 1987;60(13):1015-1019.

21. Haffner SM, Lehto S, Rönnemaa T, Pyörälä K, Laakso M. Mortality from coronary heart disease in subjects with type 2 diabetes and in nondiabetic subjects with and without prior myocardial infarction. $N$ Engl J Med. 1998;339(4):229-234.

22. Colhoun HM, Betteridge DJ, Durrington PN, et al; CARDS Investigators. Primary prevention of cardiovascular disease with atorvastatin in type 2 diabetes in the collaborative atorvastatin diabetes study (CARDS): multicentre randomised placebo-controlled trial. Lancet. 2004;364(9435): 685-696.

23. Ley SH, Harris SB, Connelly PW, et al. Utility of non-high-density lipoprotein cholesterol in assessing incident type 2 diabetes risk. Diabetes Obes Metab. 2012;14(9):821-825.

24. UK Prospective Diabetes Study (UKPDS). XI: biochemical risk factors in type 2 diabetic patients at diagnosis compared with age-matched normal subjects. Diabet Med. 1994;11(6):534-544.

25. Soran H, Schofield JD, Adam S, Durrington PN. Diabetic dyslipidaemia. Curr Opin Lipidol. 2016;27(4):313-322.

26. Chahil TJ, Ginsberg HN. Diabetic dyslipidemia. Endocrinol Metab Clin North Am. 2006;35(3):491-510, vii-viii.

27. Barter PJ, Brandrup-Wognsen G, Palmer MK, Nicholls SJ. Effect of statins on HDL-C: a complex process unrelated to changes in LDL-C: analysis of the VOYAGER Database. J Lipid Res. 2010;51(6):1546-1553. 
28. Hasvold P, Thuresson M, Sundström J, et al. Association between paradoxical HDL cholesterol decrease and risk of major adverse cardiovascular events in patients initiated on statin treatment in a primary care setting. Clin Drug Investig. 2016;36(3):225-233.

29. Frick MH, Elo O, Haapa K, et al. Helsinki Heart Study: primaryprevention trial with gemfibrozil in middle-aged men with dyslipidemia. Safety of treatment, changes in risk factors, and incidence of coronary heart disease. N Engl J Med. 1987;317(20):1237-1245.

30. Bezafibrate infarction prevention (BIP) study. Secondary prevention by raising HDL cholesterol and reducing triglycerides in patients with coronary artery disease. Circulation. 2000;102(1):21-27.

31. Robins SJ, Collins D, Wittes JT, et al; VA-HIT Study Group. Veterans affairs high-density lipoprotein intervention trial. Relation of gemfibrozil treatment and lipid levels with major coronary events: VA-HIT: a randomized controlled trial. JAMA. 2001;285(12):1585-1591.

32. Scott R, O'Brien R, Fulcher G, et al; Fenofibrate Intervention and Event Lowering in Diabetes (FIELD) Study Investigators. Effects of fenofibrate treatment on cardiovascular disease risk in 9,795 individuals with type 2 diabetes and various components of the metabolic syndrome: the fenofibrate intervention and event lowering in diabetes (FIELD) study. Diabetes Care. 2009;32(3):493-498.

33. Ginsberg HN, Elam MB, Lovato LC, et al; The ACCORD Study Group. Effects of combination lipid therapy in type 2 diabetes mellitus. $N$ Engl J Med. 2010;362(17):1563-1574.

34. Boden WE, Probstfield JL, Anderson T, et al; AIM-HIGH Investigators Niacin in patients with low HDL cholesterol levels receiving intensive statin therapy. $N$ Engl J Med. 2011;365(24):2255-2267.

35. Guyton JR, Slee AE, Anderson T, et al. Relationship of lipoproteins to cardiovascular events: the AIM-HIGH Trial (Atherothrombosis Intervention in Metabolic Syndrome With Low HDL/High Triglycerides and Impact on Global Health Outcomes). J Am Coll Cardiol. 2013;62(17):1580-1584.

36. Tirkkonen T, Ryynänen A, Vahlberg T, et al. Frequency and clinical relevance of drug interactions with lovastatin and simvastatin: an observational database study. Drug Saf. 2008;31(3):231-240.

37. Lawson LD, Hughes BG. Human absorption of fish oil fatty acids as triacylglycerols, free acids, or ethyl esters. Biochem Biophys Res Commun. 1988;152(1):328-335.

38. Lawson LD, Hughes BG. Absorption of eicosapentaenoic acid and docosahexaenoic acid from fish oil triacylglycerols or fish oil ethyl esters co-ingested with a high-fat meal. Biochem Biophys Res Commun. 1988;156(2):960-963.

39. Beckermann B, Beneke M, Seitz I. Comparative bioavailability of eicosapentaenoic acid and docasahexaenoic acid from triglycerides, free fatty acids and ethyl esters in volunteers. Arzneimittelforschung. 1990;40(6):700-704.

40. Davidson MH, Johnson J, Rooney MW, Kyle ML, Kling DF. A novel omega-3 free fatty acid formulation has dramatically improved bioavailability during a low-fat diet compared with omega-3-acid ethyl esters

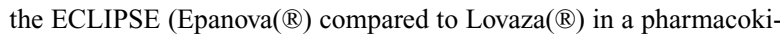
netic single-dose evaluation) study. J Clin Lipidol. 2012;6(6):573-584.

41. Offman E, Marenco T, Ferber S, et al. Steady-state bioavailability of prescription omega-3 on a low-fat diet is significantly improved with a free fatty acid formulation compared with an ethyl ester formulation: the ECLIPSE II study. Vasc Health Risk Manag. 2013;9:563-573.

42. Piepoli MF, Hoes AW, Agewall S, et al. 2016 European Guidelines on cardiovascular disease prevention in clinical practice: The sixth joint task force of the European society of cardiology and other societies on cardiovascular disease prevention in clinical practice (constituted by representatives of 10 societies and by invited experts): developed with the special contribution of the European association for cardiovascular prevention \& rehabilitation (EACPR). Eur Heart J. 2016;37(29):2315-2381.

43. Kastelein JJ, Maki KC, Susekov A, et al. Omega-3 free fatty acids for the treatment of severe hypertriglyceridemia: the EpanoVa fOr Lowering Very high triglyceridEs (EVOLVE) trial. J Clin Lipidol. 2014;8(1):94-106.

44. Epanova ${ }^{\circledR}$ (omega-3 carboxylic acids) [prescribing information]. New Jersey: Omthera Pharmaceuticals, Inc; 2015.
45. Pischon T, Girman CJ, Sacks FM, Rifai N, Stampfer MJ, Rimm EB. Non-high-density lipoprotein cholesterol and apolipoprotein B in the prediction of coronary heart disease in men. Circulation. 2005;112(22): 3375-3383.

46. Mori TA, Burke V, Puddey IB, Watts GF, O’Neal DN, Best JD, Beilin LJ. Purified eicosapentaenoic and docosahexaenoic acids have differential effects on serum lipids and lipoproteins, LDL particle size, glucose, and insulin in mildly hyperlipidemic men. Am J Clin Nutr. 2000; 71(5):1085-1094.

47. Leigh-Firbank EC, Minihane AM, Leake DS, et al. Eicosapentaenoic acid and docosahexaenoic acid from fish oils: differential associations with lipid responses. Br J Nutr. 2002;87(5):435-445.

48. Kelley DS, Siegel D, Vemuri M, Mackey BE. Docosahexaenoic acid supplementation improves fasting and postprandial lipid profiles in hypertriglyceridemic men. Am J Clin Nutr. 2007;86(2):324-333.

49. Maki KC, Van Elswyk ME, McCarthy D, et al. Lipid responses to a dietary docosahexaenoic acid supplement in men and women with below average levels of high density lipoprotein cholesterol. J Am Coll Nutr. 2005;24(3):189-199.

50. Bays HE, Ballantyne CM, Braeckman RA, Stirtan WG, Soni PN. Icosapent ethyl, a pure ethyl ester of eicosapentaenoic acid: effects on circulating markers of inflammation from the MARINE and ANCHOR studies. Am J Cardiovasc Drugs. 2013;13(1):37-46.

51. Harris WS, Miller M, Tighe AP, Davidson MH, Schaefer EJ. Omega-3 fatty acids and coronary heart disease risk: clinical and mechanistic perspectives. Atherosclerosis. 2008;197(1):12-24.

52. Davidson MH. Mechanisms for the hypotriglyceridemic effect of marine omega-3 fatty acids. Am J Cardiol. 2006;98(4A):27i-33i.

53. Davidson MH, Stein EA, Bays HE, et al; COMBination of prescription Omega-3 with Simvastatin (COMBOS) Investigators. Efficacy and tolerability of adding prescription omega-3 fatty acids $4 \mathrm{~g} / \mathrm{d}$ to simvastatin $40 \mathrm{mg} / \mathrm{d}$ in hypertriglyceridemic patients: an 8-week, randomized, double-blind, placebo-controlled study. Clin Ther. 2007;29(7): 1354-1367.

54. Maki KC, Orloff DG, Nicholls SJ, et al. A highly bioavailable omega-3 free fatty acid formulation improves the cardiovascular risk profile in high-risk, statin-treated patients with residual hypertriglyceridemia (the ESPRIT trial). Clin Ther. 2013;35(9):1400-1411.e1-e3.

55. Nakamura N, Hamazaki T, Jokaji H, Minami S, Kobayashi M. Effect of HMG-CoA reductase inhibitors on plasma polyunsaturated fatty acid concentrations in patients with hyperlipidemia. Int J Clin Lab Res. 1998; 28(3):192-195.

56. Dunbar RL, Nicholls SJ, Maki KC, et al. Effects of omega-3 carboxylic acids on lipoprotein particles and other cardiovascular risk markers in high-risk statin-treated patients with residual hypertriglyceridemia: a randomized, controlled, double-blind trial. Lipids Health Dis. 2015;14:98.

57. Davidson MH, Rooney MW, Drucker J, Eugene Griffin H, Oosman S, Beckert M; LCP-AtorFen Investigators. Efficacy and tolerability of atorvastatin/fenofibrate fixed-dose combination tablet compared with atorvastatin and fenofibrate monotherapies in patients with dyslipidemia: a 12-week, multicenter, double-blind, randomized, parallel-group study. Clin Ther. 2009;31(12):2824-2838.

58. Yokoyama M, Origasa H, Matsuzaki M, et al; Japan EPA Lipid Intervention Study (JELIS) Investigators. Effects of eicosapentaenoic acid on major coronary events in hypercholesterolaemic patients (JELIS): a randomised open-label, blinded endpoint analysis. Lancet. 2007; 369(9567):1090-1098.

59. Bruckert E, Hayem G, Dejager S, Yau C, Bégaud B. Mild to moderate muscular symptoms with high-dosage statin therapy in hyperlipidemic patients - the PRIMO study. Cardiovasc Drugs Ther. 2005;19(6): 403-414.

60. Braeckman RA, Stirtan WG, Soni PN. Effect of concomitant icosapent ethyl (eicosapentaenoic acid ethyl ester) on the pharmacokinetics of atorvastatin. Clin Drug Investig. 2015;35(1):45-51.

61. McKenney JM, Swearingen D, Di Spirito M, et al. Study of the pharmacokinetic interaction between simvastatin and prescription omega-3-acid ethyl esters. J Clin Pharmacol. 2006;46(7):785-791. 
62. Gosai P, Liu J, Doyle RT, Johnson J, Carter R, Sica D, McKenney JM. Effect of omega-3-acid ethyl esters on the steady-state plasma pharmacokinetics of rosuvastatin in healthy adults. Expert Opin Pharmacother. 2008;9(17):2947-2953.
63. Di Spirito M, Morelli G, Doyle RT, Johnson J, McKenney J. Effect of omega-3-acid ethyl esters on steady-state plasma pharmacokinetics of atorvastatin in healthy adults. Expert Opin Pharmacother. 2008;9(17): 2939-2945.

\section{Publish your work in this journal}

Vascular Health and Risk Management is an international, peerreviewed journal of therapeutics and risk management, focusing on concise rapid reporting of clinical studies on the processes involved in the maintenance of vascular health; the monitoring, prevention and treatment of vascular disease and its sequelae; and the involvement of metabolic disorders, particularly diabetes. This journal is indexed on PubMed Central and MedLine. The manuscript management system is completely online and includes a very quick and fair peer-review system, which is all easy to use. Visit http://www.dovepress.com/ testimonials.php to read real quotes from published authors. 